\title{
THE IMPACT OF 2-AMINOETHANESULFONIC ACID, GUARANINE METHYL THEOBROMINE 1, 3, 7-TRIMETHYLXANTHINE THEINE AND/OR ISOBUTYLPHENYL PROPIONIC ACID ON MASCULINE FECUNDITY, AND MORPHOPATHOLOGICAL DISORDERS IN RATS
}

\author{
WAEL ABU DAYYIH ${ }^{1 *}$, YAZAN S BATARSEH ${ }^{1}$, ZAINAB ZAKAREIA ${ }^{1}$, MOHAMED HAMMAD ${ }^{2}$, KAMAL MANSI ${ }^{3}$, \\ WALID ABU RAYYAN ${ }^{1 *}$
}

${ }^{1}$ Department of Pharmaceutical Medicinal Chemistry and Pharmacognosy, Faculty of Pharmacy and Medical Sciences, University of Petra, Amman, Jordan. ${ }^{2}$ Department of Basic Sciences, College of Science and Health Professions, King Saud Bin Abdulaziz University for Health Sciences, Jeddah, Kingdom of Saudi Arabia. ${ }^{3}$ Department of Laboratory Medical Sciences, Faculty of Science, Al al-Bayt University, Mafraq, Jordan. Email: walid.aburayyan@uop.edu.jo/wabudayyih@uop.edu.jo

Received: 13 July 2019, Revised and Accepted: 23 September 2019

\section{ABSTRACT}

Objectives: This study aims to evaluate the impact of caffeine (CAF), taurine (TUR), and ibuprofen (IBF) consumption on the masculine fecundity in rats and fetuses development.

Methods: The $1^{\text {st }}$ group was kept as a normal control received distilled water. The $2^{\text {nd }}, 3^{\text {rd }}$, and $4^{\text {th }}$ groups received orally $250 \mathrm{mg} / \mathrm{kg}$, $40 \mathrm{mg} / \mathrm{kg}$, and $270 \mathrm{mg} / \mathrm{kg}$ of TUR, CAF, and IBF, respectively. In addition, the $5^{\text {th }}, 6^{\text {th }}, 7^{\text {th }}$, and $8^{\text {th }}$ groups received TUR with CAF, TUR with IBF, CAF with IBF, and TUR, CAF, IBF combination, for 45 days. Blood samples were taken to determine testosterone and follicle-stimulating hormone levels and oxidation levels. Moreover, in testes, malondialdehyde and nitrite/nitrate were estimated. Besides, the abnormality of sperms, sperm counts, and percentage of sperm motilities was characterized. These masculines were allowed to mate with untreated masculine rats to determine the rate of pregnancy and study any malformation in their fetuses.

Results: The study revealed that each of CAF and/or IBF decreased the weights of fetuses, as well as sperm counts and motilities significantly. Besides, percentages of head and tail abnormalities were increased in CAF and/or IBF. The histopathological examination revealed the presence of marked degenerative changes in testes in CAF and/or IBF-treated groups.

Conclusion: CAF and IBF have a teratogenic effect on spermatozoa and masculine fecundity, whereas TUR almost improved undesirable impacts induced by IBF or/and CAF.

Keywords: Caffeine, Taurine, Ibuprofen, Fecundity, Masculine, Teratogenicity, Rats.

(C) 2019 The Authors. Published by Innovare Academic Sciences Pvt Ltd. This is an open access article under the CC BY license (http://creativecommons. org/licenses/by/4. 0/) DOI: http://dx.doi.org/10.22159/ajpcr.2019.v12i11.34898

\section{INTRODUCTION}

Caffeine (CAF), 1, 3, 7-trimethylxanthine, is considered one of the most commonly prescribed natural remedies in the world for its stimulating effects on the brain and nervous system [1,2]. Therefore, it is a major part of several consumable foods and drinks, including chocolates, tea, and most famously coffee products. In clinical practice, CAF has been suggested to be an effective muscle relaxant, increase urination, and reduce pain, in addition to showing partial effects on neurodegenerative disorders such as Parkinson's and Alzheimer's diseases [2,3]. Several cellular pathways are involved in the observed effects of CAF mediated actions including cAMP phosphodiesterase, phosphatidylinositol- 3kinase, and A1-A2A adenosine receptors antagonistic effect [4].

Taurine (TUR), 2-aminoethane sulfonic acid, is one of the most abundant amino acids in mammals and it has a major function in vital cellular pathways. Moreover, it has been shown to be involved in neurotransmission, osmotic regulation, and reducing oxidative stress $[5,6]$.

TUR is vital for the structure and function of the brain and the retina during developmental age, in addition to having an essential role in electrolytes balance mainly calcium regulation. Moreover, TUR has a major role in reproduction and cellular membrane stability in several organs such as the brain, heart, eyes, muscular tissue, and the immune system [7]. Furthermore, TUR has shown to reduce oxidative stress by scavenging endogenous oxygen free radical molecules by being a hydrogen atom acceptor leading to enhancements in cellular viability through inhibiting apoptosis pathways [8].

Ibuprofen (IBF), part of the nonsteroidal anti-inflammatory drugs (NSAIDs), has earned its therapeutic value as a major symptom reliever for patients suffering from rheumatic related diseases $[9,10]$. Interestingly, although there have been increasing concerns about the potentially harmful adverse effects of NSAIDs [11,12], IBF is still one of the most prescribed medications for its approved indications [13]. A possible explanation may be related to the fact that IBF replaced agents that had worse side effect profiles such as glucocorticoids hormonal therapy and the use of older generation NSAIDs with extensive gastrointestinal side effects [14].

IBF has a favorable kinetics profile, it is readily absorbed through the gastrointestinal route, further biotransformed at the liver by hydroxylation followed by phase- 2 glucuronidation and eventually eliminated in urine [15]. Increasing amounts of IBF may increase the risk of activating a toxic metabolic pathway in which cytochrome p450 oxidatively transforms IBF into $\mathrm{N}$-acetyl-p-benzoquinone imine (NAPQ) [14], leading to increased cellular oxidation and eventual cell death. The liver is one of the most affected organs to such toxicity leading to fulminant liver failure. However, these effects may also have a negative impact on the gonadotrophic process, especially that evidence has suggested a negative impact of IBF on nitric oxide production which is vital for the reproduction of masculine rats [16] 
Here, we aim to investigate the impact of CAF and/or TUR on masculine fecundity and fetus development in rats. Both studied compounds are part of commercial energy drinks. Moreover, recently, the use of energy drinks has been identified as a high CAF source which raises concerns on the wide use of these beverages. In addition, energy drinks overuse has been associated with seizures and arrhythmias $[17,18]$, affect conductance and refractoriness on the heart, resulting in the development of various arrhythmias [19]. Moreover, the consuming pattern of CAF is highly intimate with doping effect. On the other hand, IBF is consumed over the counter hand in hand with energy drinks part of stress coping mechanisms. Eventually, this study will be the first study exploring the effect of the combined consumption of CAF and/or TUR with IBF, highlighting the deleterious synergistic effect on masculine fecundity and fetus development in rats.

\section{METHODS}

\section{Animals}

Adult sexually mature male rats of the Sprague-Dawley species of both sexes weighing from 150 to $200 \mathrm{~g}$ obtained from the animal house of the University of Petra (Amman, Jordan) were used in the study. Animals were housed ad libitum for at least 1 week in the laboratory room before testing under controlled environmental conditions; constant temperature $\left(25 \pm 2^{\circ} \mathrm{C}\right)$, humidity $(60 \pm 10 \%)$, and alternating $12 \mathrm{~h}$ light/dark cycles. The investigation complies with the Guide for Care and Use of Laboratory Animals published by the US National Institutes of Health (NIH Publication No. 85 - 23, revised 1996).

Sixty-four rats were randomly allocated into eight groups $(n=8)$. The $1^{\text {st }}$ group (control) received $1 \mathrm{ml} / \mathrm{kg}$ of distilled water. The $2^{\text {nd }}, 3^{\text {rd }}$, and $4^{\text {th }}$ groups received oral $250 \mathrm{mg} / \mathrm{kg}, 40 \mathrm{mg} / \mathrm{kg}$, and $270 \mathrm{mg} / \mathrm{kg}$ of TUR, CAF, and IBF, respectively. In addition, the $5^{\text {th }}, 6^{\text {th }}, 7^{\text {th }}$, and $8^{\text {th }}$ groups received TUR with IBF, TUR with CAF, CAF with IBF, and TUR with CAF with $I B F$, respectively, for $45^{\text {th }}$ consecutive days.

\section{Estimated parameters}

Impact of the tested treatments on masculine fecundity

The impact of the tested chemicals on masculine fecundity was studied by epididymal spermatozoa examination as well as histopathological examination of the testes.

\section{Epididymal spermatozoa examination}

The epididymal content was obtained immediately after sacrificing each rat. The tail of epididymis was cut with a sharp blade, squeezed gently in a clean watch-glass, and examined using the following parameters.

\section{Progressive motility of sperms}

The progressive motility of sperms was estimated according to the method reported by Bearden and Fluquary [20]. A small droplet of epididymal content was added to one drop of $2.9 \%$ sodium citrate solution on a clear glass slide, and then the slide was gently warmed. Several fields were quickly examined under a microscope $(\times 100)$ and the progressive motility of sperms was estimated as a percentage.

\section{Sperm cell concentration (sperm count)}

This was performed according to a previous technique [21]. The pipette of counting erythrocytes by hemocytometer was used. The epididymal content was withdrawn up to the mark 0.1 and the pipette was then filled up to the mark 101 by $0.9 \%$ sodium citrate solutions. The content of the pipette was mixed and shacked well by holding the ends of the pipette between the thumb and the index fingers. A cover slide was placed over the counting chamber and a drop of diluted epididymal content was spread between the hemocytometer chamber and the cover slide. The sperms in five large squares were counted using the high power objective lens $(\times 400)$. The total size in five small squares was multiplied by millions.

Epididymal sperm abnormalities

A drop from the epididymal content of each rat was immediately taken and mixed with an equal drop of eosin-nigrosine stain for detection of dead and malformed sperm. The semen was carefully mixed with the stain, then films were examined at random per slide under $\times 200$, and the sperm abnormalities were recorded.

\section{Determination of testosterone and follicle-stimulating hormone (FSH) levels}

Blood samples were taken from each rat on the $45^{\text {th }}$ day to determine the testosterone and FSH levels. Serum levels of both were assayed using rat ELISA kit (Cusabio ${ }^{\circledR}$, China) according to the manufacturer procedure.

\section{Biochemical measurements for oxidative stress biomarkers as} compared to control rats

In fact, serum total pro-oxidantstatus was doneaccording to Erel, 2005[21]. Teste contents of malondialdehyde (MDA) and total tissue nitrite/nitrate (NOx) content were estimated according to the manufacturer's prescripts using reagent kits (Bio-diagnostics, Amman, Jordan).

Impact of the tested chemicals on rate of pregnancy, weights of fetuses, and malformation in the fetus

In the past week of treatment, masculine rats of all groups are allowed to mate with females to determine the pregnancy rate and the impact of the chemicals used on their fetuses.

Feminine of 11-13 weeks old was selected for the actual study and vaginal smears were prepared every morning and examined under the light microscope (according to the method of Barth et al. [22], for 5 days to select the feminine with regular estrus. Two feminine were selected and caged together with one masculine overnight under the controlled environmental condition of temperature $\left(25 \pm 2^{\circ} \mathrm{C}\right)$, humidity $(60 \pm 20 \%)$, and light (12 lights-12 dark cycles). The 0 day of gestation was determined by the presence of sperms in the vaginal smear [23]. Pregnant rats of all groups were kept under observation until the $20^{\text {th }}$ day of gestation then-pregnant rats were sacrificed under light ether anesthesia. All fetuses were examined for the occurrence of any malformation and weighed. Total implantation sites, the fetal mortality rate (resorbed or stillbirth) and living fetuses were recorded

\section{Histopathological examination}

After fixation of testes in $10 \%$ formalin/saline for $24 \mathrm{~h}$, testes tissues were embedded in paraffin wax and cut at $5 \mu \mathrm{m}$ thickness. Sections were processed, stained by hematoxylin and eosin stain for histopathological examination using the light microscope.

\section{Statistical analysis}

Data were expressed as meanststandard error of the means (SEM). Comparisons between means were carried out using one-way ANOVA followed by Tuke-Kramer multiple comparisons test. Statistical analysis was performed SPSS version 25; a probability level of $<0.05$ was accepted as statistically significant.

\section{RESULTS}

The current study examined toxicological impacts of the combination of CAF and TUR which are already present in certain energy products, as well as the impact of receiving daily IBF as an over the counter treatment, on testis and fetuses of rats.

Impacts of tested treatments on sperm count and motility as well as serum levels of testosterone and FSH

Noteworthy, the administration of IBF caused a significant decrease in the sperm count alone (56\%) or in combination with CAF $(61 \%)$ as compared to the control group, whereas the addition of TUR improved sperm counts. Interestingly, TUR with IBF declined sperm count by $36 \%$ and TUR, CAF, and IBF declined it by $43 \%$ as compared to the control group (Fig. 1a).

Moreover, the administration of IBF caused a significant decrease in the sperm motility alone or in combination with CAF as compared to the control group. While, TUR enhanced sperm motility where TUR with 


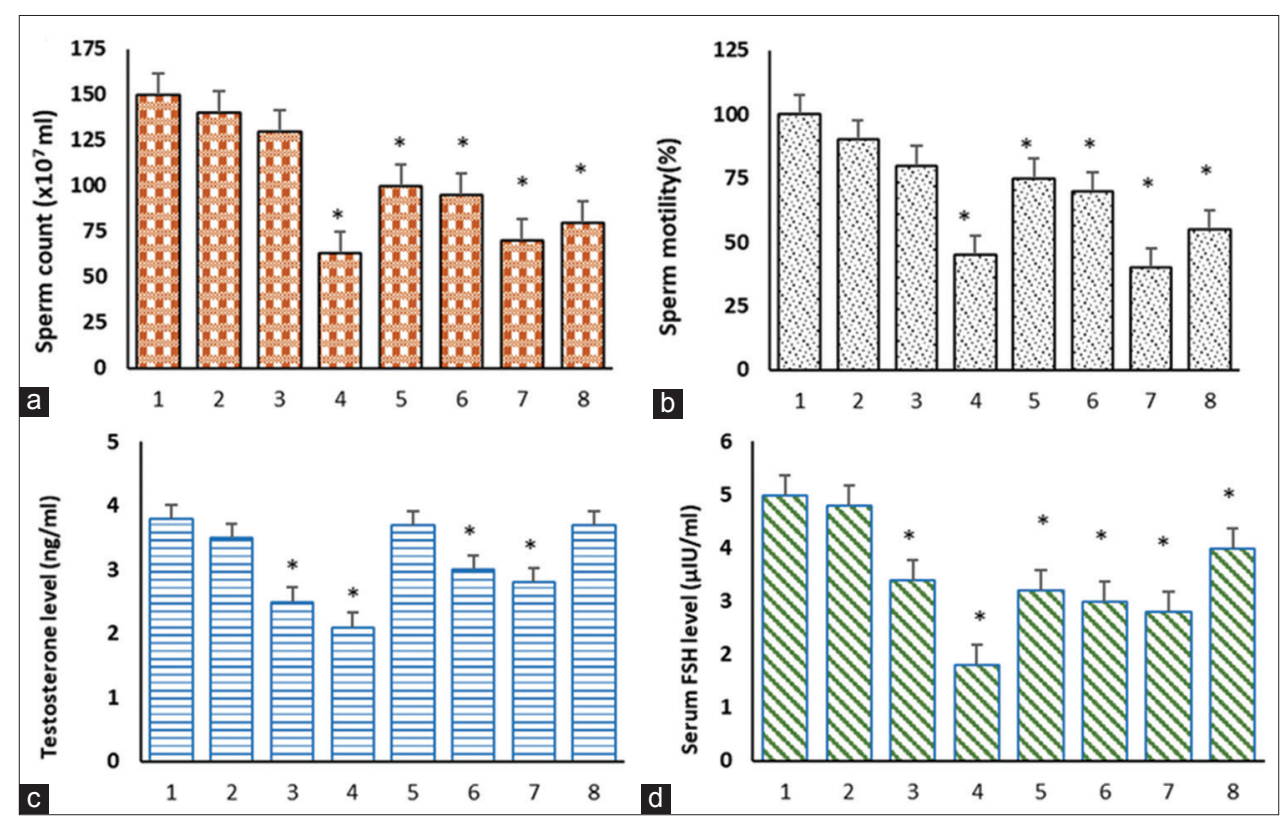

Fig. 1: Impacts of tested treatments on sperm count as compared with control rats (a). Impacts of tested treatments on sperm motility percentage as compared with control rats (b). Impacts of tested treatments on testosterone level as compared with control rats (c). Impacts of tested treatments on FSH level as compared with control rats (d). The $1^{\text {st }}$ group was kept as a normal control received $1 \mathrm{ml} / \mathrm{kg}$ distilled water. The $2^{\text {nd }}, 3^{\text {rd }}$, and $4^{\text {th }}$ groups received $250 \mathrm{mg} / \mathrm{kg}, 40 \mathrm{mg} / \mathrm{kg}$, and $270 \mathrm{mg} / \mathrm{kg}$; orally of TUR, CAF, and IBF, respectively. In addition, the $5^{\text {th }}, 6^{\text {th }} 7^{\text {th }}$, and $8^{\text {th }}$ groups received TUR with IBF, TUR with CAF, CAF with IBF, and TUR with CAF with IBF, respectively, for $45^{\text {th }}$ consecutive days. Where is: 1-Control, 2-TUR, 3-CAF, 4-IBF, 5-TUR with CAF, 6-TUR with IBF, 7-IBF with CAF, and 8-TUR with CAF with IBF. Each bar with vertical line represents the mean \pm SEM of 6-8 rats per group. *vs. Control group, (one-way ANOVA followed by Tukey-Kramer multiple comparisons test; *p<0.05). TUR: Taurine, CAF: Caffeine, and IBF: Ibuprofen

IBF as well as TUR, CAF, and IBF combination reduced sperm motility compared to the control group (Fig. 1b).

Markedly, the administration of IBF and CAF caused a significant decrease in testosterone level alone by $42 \%$ and $34 \%$, respectively, or in a combination of $36 \%$ as compared to the control group, whereas the addition of TUR improved testosterone level where TUR with IBF declined testosterone level by $26 \%$ and TUR, CAF, and IBF combination declined it by $16 \%$ compared to the control group (Fig. 1c).

Likewise, the administration of IBF and CAF caused a significant decrease in FSH level alone by $62 \%$ and $34 \%$, respectively, or in combination with $59 \%$ as compared to the control group. While the addition of TUR enhanced FSH level where TUR with IBF declined FSH level by $52 \%$, and TUR with CAF and IBF declined it by $22 \%$ as compared to the control group (Fig. 1d).

\section{Abnormalities of head and tail of sperm formation}

In fact, using eosin and nigrosine stain revealed photomicrograph of smear from the seminal fluid of none treated rat in the control group showing normal sperm formation with head, neck, and tail. However, photomicrograph from CAF-treated group showed coiled tail sperm. Sperms in IBF-treated group demonstrated double head sperms. Further masculine rats received TUR with IBF showed kinked or coiled tail and round head. Moreover, coiled tail sperm; coiled neck and detached head in rats were given CAF with IBF. Meanwhile, photomicrograph of CAF with TUR-treated group revealed a double head and pairing phenomenon. In the last photomicrograph, we found that misshapen head with flattened head sperms in TUR with CAF with IBF-treated group (Fig. 2).

\section{Impacts of tested treatments on oxidative stress biomarkers}

Obviously, in Fig. 3, the administration of IBF and CAF caused a significant increase in total pro-oxidant contents alone to 4 folds and 2 folds, respectively, or in combination to 3 folds as compared to control group. Whereas, the addition of TUR improved total pro-oxidant

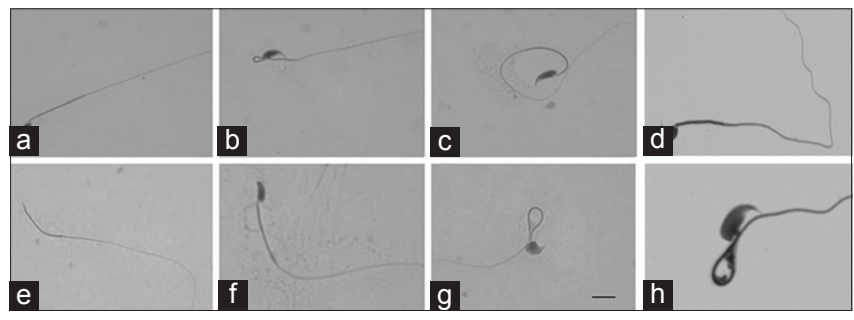

Fig. 2: Impacts of tested treatments on sperm formation in masculine rats showing that abnormalities of head, neck, and tail of sperms. The $1^{\text {st }}$ group was kept as a normal control received

$1 \mathrm{ml} / \mathrm{kg}$ distilled water. The $2^{\text {nd }}, 3^{\text {rd }}$, and $4^{\text {th }}$ groups received $250 \mathrm{mg} / \mathrm{kg}, 40 \mathrm{mg} / \mathrm{kg}$, and $270 \mathrm{mg} / \mathrm{kg}$; orally of TUR, CAF, and IBF, respectively. In addition, the $5^{\text {th }}, 6^{\text {th }}, 7^{\text {th }}$, and $8^{\text {th }}$ groups received TUR with IBF, TUR with CAF, CAF with IBF, and TUR with CAF with IBF, respectively, for $45^{\text {th }}$ consecutive days. Where is: (a) Sperm of control male, (b) sperm of a male which taken CAF, (c) sperm of male which taken IBF, (d) sperm of a male which taken TUR and IBF, (e) sperm of male which taken CAF and IBF, (f) sperm of male which taken CAF and TUR, (g) sperm of male which taken CAF and TUR and IBF, (h) fetus of male which taken CAF andTUR and IBF

contents where TUR with IBF declined it by 3 folds, and TUR with CAF with IBF declined it by 2 folds as compared to the control group.

Similarly, the administration of IBF caused a significant rising in MDA content $29 \%$, or in combination with CAF by $30 \%$ as compared to the control group. In addition, NOx content increased significantly after administration of IBF by $20 \%$ as compared to the control group.

Impact on the rate of pregnancy and weights of fetuses

In the actual study, Fig. 4 a revealed that IBF alone and in combination with CAF diminished the rate of pregnancy markedly by $50 \%$ as compared to the control group. TUR improved this percentage when 
combined with IBF as well as with CAF and IBF to become $67 \%$ as compared to the control group.

Moreover, Fig. 4b illustrated that the weight of fetuses decreased significantly in IBF-, CAF-, and CAF with IBF-treated groups as compared to control group by $27 \%, 22 \%$, and $30 \%$, correspondingly. In addition, we found that TUR improved the weight of fetuses in TUR with CAF-, and TUR with IBF-treated groups to decline by $19 \%$ and $18 \%$, respectively, as compared to the control group. At the same time, TUR did not enhance the reduction in weight (29\%) in TUR with CAF with IBF-treated group as compared to the control group.

\section{Malformation in fetus}

Fig. 5 showed that fetuses obtained from control pregnant rats on $20^{\text {th }}$ day of gestation normal fetus showing normal growth. On the other hand, fetuses belonged to IBF demonstrated hematoma and wrinkled skin or contraction, CAF revealed loss of foot due to a severe hematoma, TUR with CAF showed paralysis in forelimb, as well as TUR with CAF with IBF, and demonstrated paralysis in forelimb and hematoma on a hind limb with contraction in all over the body.
Photomicrographs showed that fetuses belonged to IBF has hematoma and wrinkled skin or contraction, CAF revealed loss of a foot, TUR with CAF showed paralysis in the forelimb, as well as TUR with CAF with IBF, and demonstrated paralysis in forelimb and hematoma on a hind limb with contraction in all over the body. Where, TUR: Taurine, CAF: Caffeine, and IBF: Ibuprofen.

\section{Histopathological examination of testes of masculine rats} Histopathological findings of tissues were illustrated in Fig. 6.

In fact, the histopathological examination of sections of the control group showed a normal histological structure of seminiferous tubules with complete spermatogenesis and sperm production. Likewise, rats received TUR showed no histopathological changes. However, CAF administration showed degeneration of spermatogonial cells lining seminiferous tubule and congestion of interstitial blood vessels. In addition, administration of IBF to rats revealed degeneration of spermatogonial cells lining seminiferous tubules with the formation of spermatic giant cells. However, testis of TUR with CAF-treated group showed that no histopathological changes. Rats received TUR

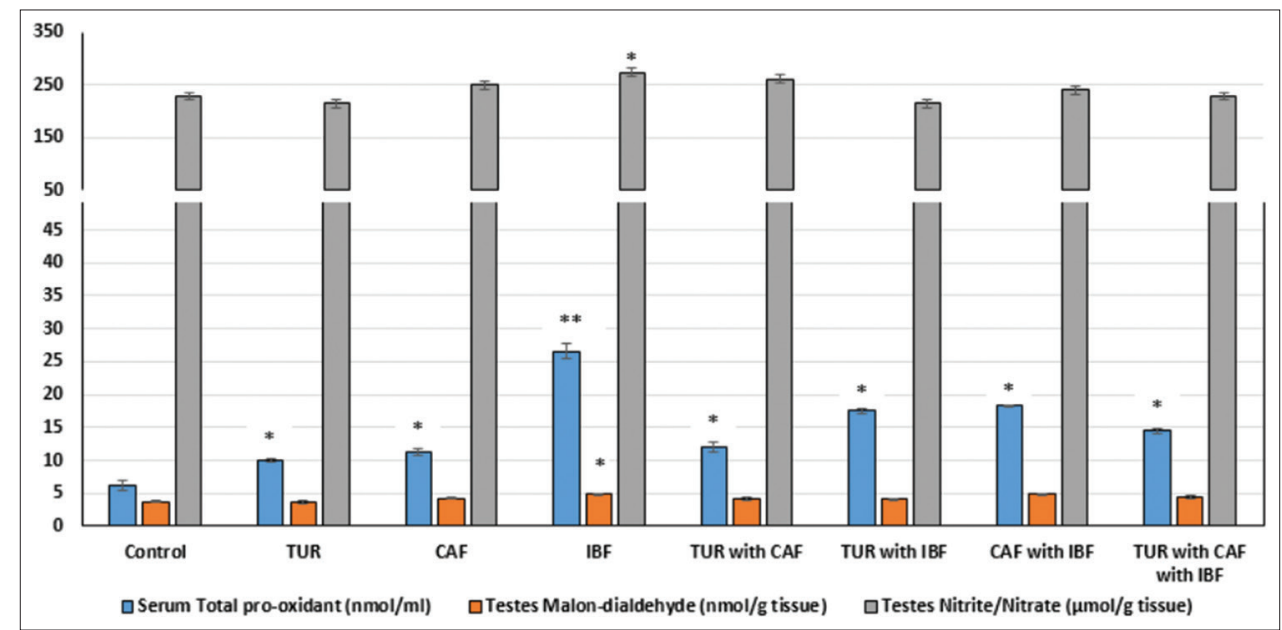

Fig. 3: Impacts of tested treatments on oxidative stress biomarkers. The levels of pro-oxidants in serum, MDA in tests, and nitrite in tests were measured in eight rat groups. The $1^{\text {st }}$ group was kept as a normal control received $1 \mathrm{ml} / \mathrm{kg}$ distilled water. The $2^{\text {nd }}, 3^{\text {rd }}$, and $4^{\text {th }}$ groups received $250 \mathrm{mg} / \mathrm{kg}, 40 \mathrm{mg} / \mathrm{kg}$, and $270 \mathrm{mg} / \mathrm{kg}$; orally of TUR, CAF, and IBF, respectively. In addition, the $5^{\text {th }}, 6^{\text {th }}, 7^{\text {th }}$, and $8^{\text {th }}$ groups received TUR with IBF, TUR with CAF, CAF with IBF, and TUR with CAF with IBF, respectively, for $45^{\text {th }}$ consecutive days. $\left({ }^{*} p<0.05\right.$ and $\left.{ }^{* *} p<0.001\right)$.

Values are expressed as mean \pm SEM of 6-8 rats per group. *vs. Control group, (one-way ANOVA followed by Tukey-Kramer multiple comparisons test; $\mathbf{p}<0.05)$. TUR: Taurine, CAF: Caffeine, and IBF: Ibuprofen

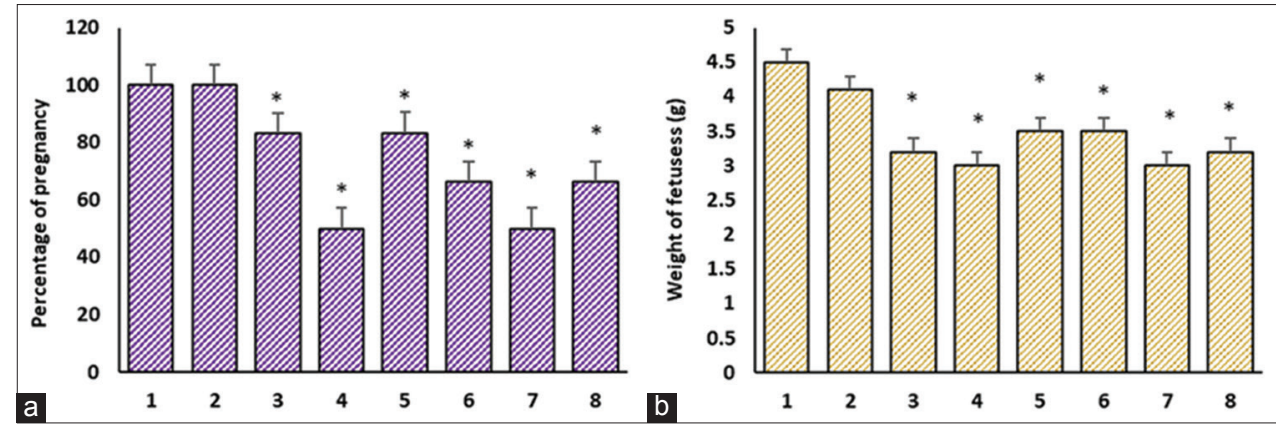

Fig. 4: Impacts of tested treatments which were given to masculine rats on the percentage of pregnancy in masculine rats as compared with control rats (a). Impacts of tested treatments which were given to masculine rats on the weight of fetuses as compared with control rats (b), the fetuses obtained from pregnant rats on $20^{\text {th }}$ day of gestation. The $1^{\text {st }}$ group was kept as a normal control received $1 \mathrm{ml} /$ $\mathrm{kg}$ distilled water. The $2^{\text {nd }}, 3^{\text {rd }}$, and $4^{\text {th }}$ groups received $250 \mathrm{mg} / \mathrm{kg}, 40 \mathrm{mg} / \mathrm{kg}$, and $270 \mathrm{mg} / \mathrm{kg}$; orally of TUR, CAF, and IBF, respectively. In addition, the $5^{\text {th }}, 6^{\text {th }}, 7^{\text {th }}$, and $8^{\text {th }}$ groups received TUR with IBF, TUR with CAF, CAF with IBF, and TUR with CAF with IBF, respectively, for $45^{\text {th }}$ consecutive days. Where is: 1-Control, 2-TUR 3-CAF, 4-IBF, 5-TUR with CAF, 6-TUR with IBF, 7-IBF with CAF, and 8-CAF with TUR with IBF. Each bar with a vertical line reactuals the mean \pm SEM of 6-8 rats per group. *vs. Control group, (one-way ANOVA followed by Tukey-Kramer multiple comparisons test; ${ }^{*}$ p<0.05). TUR: Taurine, CAF: Caffeine, and IBF: Ibuprofen 
with IBF showed that congestion of interstitial blood vessels. Besides the administration of IBF with CAF showed marked degeneration of spermatogonial cells lining seminiferous tubules, interstitial edema, and congestion of interstitial blood vessels. On the other hand, administration of TUR with CAF with IBF to rats revealed marked degeneration of spermatogonial cells lining seminiferous tubules and interstitial edema.

Photomicrographs showed that the histopathological examination of sections of the control group showed a normal histological structure of seminiferous tubules with complete spermatogenesis and sperm production. Likewise, rats received TUR showed no histopathological changes. However, CAF administration showed degeneration of spermatogonial cells lining seminiferous tubule and congestion of interstitial blood vessels. In addition, administration of IBF to rats revealed degeneration of spermatogonial cells lining seminiferous tubules with the formation of spermatic giant cells. However, testes of TUR with CAFtreated group showed that no histopathological changes. Rats received TUR with IBF showed that congestion of interstitial blood vessels. Besides the administration of IBF with CAF showed marked degeneration of spermatogonial cells lining seminiferous tubules, interstitial edema, and

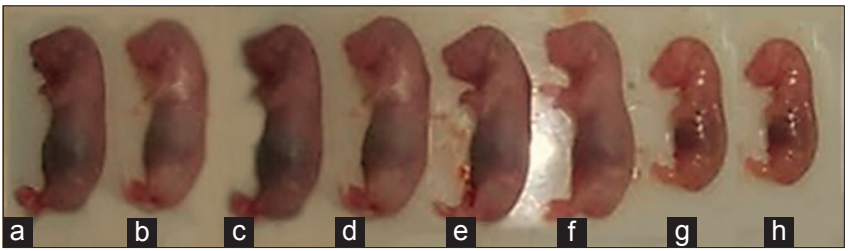

Fig. 5: Impacts of tested treatments which were given to masculine rats on malformation of fetuses as compared with control rats, the fetuses obtained from pregnant rats on $20^{\text {th }}$ day of gestation. The $1^{\text {st }}$ group was kept as a normal control received

$1 \mathrm{ml} / \mathrm{kg}$ distilled water. The $2^{\text {nd }}, 3^{\text {rd }}$, and $4^{\text {th }}$ groups received $250 \mathrm{mg} / \mathrm{kg}, 40 \mathrm{mg} / \mathrm{kg}$, and $270 \mathrm{mg} / \mathrm{kg}$; orally of TUR, CAF, and IBF respectively. In addition, the $5^{\text {th }}, 6^{\text {th }}, 7^{\text {th }}$, and $8^{\text {th }}$ groups received TUR with IBF, TUR with CAF, CAF with IBF, and TUR with CAF with IBF, respectively, for $45^{\text {th }}$ consecutive days. Where is: (a) Fetus of control male, (b) fetus of male taken CAF, (c) fetus of male taken IBF, (d) fetus of male taken TUR with IBF, (e) fetus of male taken CAF with IBF, (f) fetus of male taken CAF with TUR, (g) fetus of male taken CAF with TUR and IBF, (h) sperm of male which taken CAF and TUR and IBF congestion of interstitial blood vessels. On the other hand, administration of TUR with CAF with IBF to rats revealed marked degeneration of spermatogonial cells lining seminiferous tubules and interstitial edema, whereas TUR: Taurine, CAF: Caffeine, and IBF: Ibuprofen.

\section{DISCUSSION}

In the current work, we evaluated the effect of CAF, TUR, and/or IBF on masculine fecundity and fetus development in rats. Results suggested that IBF induced a significant reduction in sperm count and motility, markers of testicular function, and lead to degeneration in testicular tissue showed in the histopathological examination, alone or in combination with CAF and TUR. This finding suggests that IBF penetrated the blood-testis barrier changing the microenvironment of seminiferous tubules, and thus creating a different microenvironment in the inner part of the wall of the seminiferous tubules studied previously at a dose of $7.5 \mathrm{mg} / \mathrm{kg}$ in rats for 42 days, therefore, even a low dose of IBF with long duration is possibly capable of penetrating the barrier [24]. Hence, it is preferable that the continuous administration of IBF daily for a long period of time may have health consequences.

In addition, malformations of head and tail in sperm are appeared significantly. Literature suggests that abnormalities in sperm cells by small molecules could occur by one of three pathways: Physiological, cytotoxic, and genetic. The morphological abnormalities might have been related to changes in testicular DNA which interfere with the process of differentiation of spermatozoa. Furthermore, exposure to molecules or contaminants from the personal habitats as smoking could cause deleterious effects on the body rendering the production of pituitary-hypothalamic or sex hormonal imbalances could affect spermatogenesis as well [10,25-28].

In addition, the likelihood of pregnancy was significantly reduced in IBF and CAF-IBF treated groups. The noted negative impact on reproduction was induced by IBF, alone or in combination with CAF which may be due to an increase in preimplantation losses or from oligospermia (low concentration of sperms in the seminal fluid), azoospermia, impairments sperm motility, and reduction in the fertilizing potential of spermatozoa [29]. However, TUR did not affect the percentage of pregnancy as compared with the control group.

Interestingly, fetus malformation was noted significantly after the administration of IBF and it was at a lower extent in CAF-treated group. This observation may be explained by the following mechanisms by which CAF might encourage these negative impacts. Mechanisms

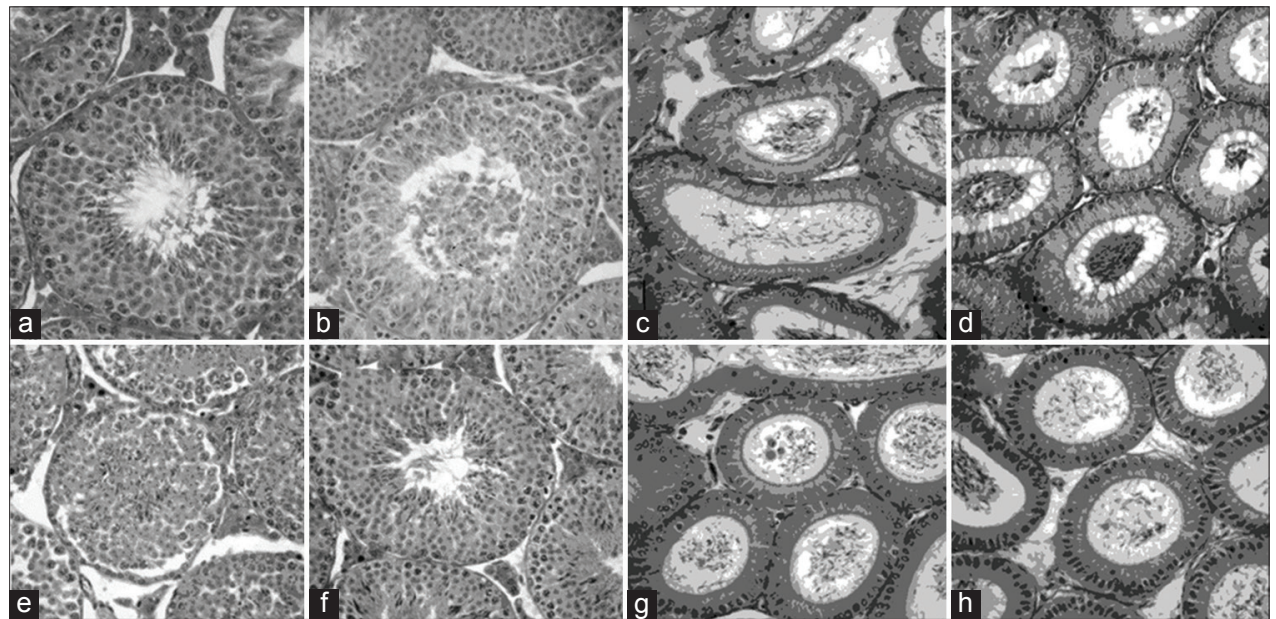

Fig. 6: Impacts of tested treatments on the histopathological examination in rat testes as compared with control rats. The $1^{\text {st }}$ group was kept as a normal control received $1 \mathrm{ml} / \mathrm{kg}$ distilled water. The $2^{\text {nd }}, 3^{\text {rd }}$, and $4^{\text {th }}$ groups received $250 \mathrm{mg} / \mathrm{kg}$, $40 \mathrm{mg} / \mathrm{kg}$, and $270 \mathrm{mg} / \mathrm{kg}$; orally of TUR, CAF, and IBF, respectively. In addition, the $5^{\text {th }}, 6^{\text {th }}, 7^{\text {th }}$, and $8^{\text {th }}$ groups received TUR with IBF, TUR with CAF, CAF with IBF, and TUR with CAF with IBF, respectively, for $45^{\text {th }}$ consecutive days. Where is: (a) Control, (b) TUR, (c) CAF, (d) IBF, (e) TUR with CAF, (f) TUR with IBF, (g) IBF with CAF, and (h) CAF with TUR with IBF. TUR: Taurine, CAF: Caffeine, and IBF: Ibuprofen 
include down-regulation of adenosine A2 receptors, leading to reduce cerebral blood flow in premature infants. However, both treatments in combination with TUR revealed notable improvement supporting the work of another study [30].

In addition, IBF and/or CAF increased testicular oxidative stress, which was revealed by augmenting of MDA content in all IBF treated groups along with an increase in NOx content. These impacts might be attributed to the activation of the enzyme, xanthine oxidase, which catalyzes the oxidation of xanthenes to uric acid, which generates superoxides, hydrogen peroxides, and free radicals [31]. Besides, albeit high doses of IBF instituted a conjugated bond with glucuronic acid or sulfate and a major portion is metabolized by the cytochrome P450 system. This probably leads to the production of reactive toxic metabolites such as NAPQI interacting with sulfhydryl groups in the glutathione molecule. Consequently, IBF induced depletion of cellular GSH stores. Binding cellular proteins, the remaining portion of NAPQI begins lipid peroxidation and ultimately induces damage [32]

In fact, the presence of TUR with IBF or/and CAF reduced the toxicity to a large extent, while the presence of IBF almost increases the toxicity. Our study has provided some data and information that may be useful for public health. There is a need for regular public health checks on the consumption of some socially acceptable analgesics compounds such as IBF or/and CAF. Furthermore, the presence of IBF and CAF at the same time of administration had a synergistic impact that significantly increased hardness of sexual health state.

\section{CONCLUSION}

The daily consumption of IBF or/and CAF has revealed masculine fecundity in rats and conferred a teratogenic effect in the fetuses. The admission of TUR almost improved undesirable impacts induced by IBF or/and CAF

\section{ACKNOWLEDGMENT}

The authors are grateful to Faculty of Pharmacy and Medical Sciences, University of Petra, for her helpful guide in realizing this research.

\section{AUTHORS' CONTRIBUTIONS}

Prof. Abu Dayyih, Dr. Abu Rayyan, and Dr. Batarseh have designed and performed the experiments. Dr. Hamad, Dr. Mansi, Mrs. Zakareia, and Mrs. Hamid were involved in manuscript editing and finalization. Prof. Abu Dayyih and Dr. Abu Rayyan have designed the entire study project, contributed to experiment finalization, implementation, manuscript editing, and finalization.

\section{CONFLICTS OF INTEREST}

The authors declare that they have no conflicts of interest.

\section{REFERENCES}

1. Ohta A, Lukashev D, Jackson EK, Fredholm BB, Sitkovsky M 1,3,7-trimethylxanthine (caffeine) may exacerbate acute inflammatory liver injury by weakening the physiological immunosuppressive mechanism. J Immunol 2007;179:7431-8

2. Benedetti MD, Bower JH, Maraganore DM, McDonnell SK, Peterson BJ, Ahlskog JE, et al. Smoking, alcohol, and coffee consumption preceding Parkinson's disease: A case-control study. Neurology 2000;55:1350-8.

3. Ross GW, Abbott RD, Petrovitch H, Morens DM, Grandinetti A, Tung KH, et al. Association of coffee and caffeine intake with the risk of Parkinson disease. JAMA 2000;283:2674-9.

4. Fredholm BB, Bättig K, Holmén J, Nehlig A, Zvartau EE. Actions of caffeine in the brain with special reference to factors that contribute to its widespread use. Pharmacol Rev 1999;51:83-133.

5. Foukas LC, Daniele N, Ktori C, Anderson KE, Jensen J, Shepherd PR, et al. Direct effects of caffeine and theophylline on p110 delta and other phosphoinositide 3-kinases. Differential effects on lipid kinase and protein kinase activities. J Biol Chem 2002;277:37124-30.
6. Harsha S, Ankita J, Harsha L, Deepak B. Anti-oxidative, antiinflammatory and anti-atherosclerotic effect of taurine on hypercholesterolemia induced atherosclerotic rats. Int J Pharm Pharm Sci 2018;10:1-6.

7. Ripps H, Shen W. Review: Taurine: A "very essential" amino acid. Mol Vis 2012;18:2673-86.

8. Nittynen L, Nurminen ML, Korpela R, Vapaatalo H. Role of arginine, taurine and homocysteine in cardiovascular diseases. Ann Med 1999;31:318-26.

9. Ye R, Wang S, Li Y, Wu R, Pei J, Wang J, et al. Primary dysmenorrhea is potentially predictive for initial orthodontic pain in female patients. Angle Orthod 2014;84:424-9.

10. Abu Rayyan W. Influence of smoking duration on cadmium deposition in blood and scalp hair among university students in Jordan. Iran J Public Health 2016;45:266-7.

11. Abualhasan MN, Assali M, Zaid AN, Jaradat NA, Tarayra R, Hamdan A, et al. Synthesis and formulation of ibuprofen pro-drugs for enhanced transdermal absorption. Int J Pharm Pharm Sci 2015;7:352-4

12. Velasco-Sosa YG, Villafuerte-Robles L. Effect of components and deposition on technological performance of ibuprofen tablets. Int $\mathrm{J}$ Appl Pharm 2018;10:62-8.

13. Kohli SS, Kohli VS. Effectiveness of piroxicam and ibuprofen premedication on orthodontic patients' pain experiences. Angle Orthod 2011;81:1097-102.

14. Xiaoting L, Yin T, Yangxi C. Interventions for pain during fixed orthodontic appliance therapy. A systematic review. Angle Orthod 2010;80:925-32

15. Grahame-Smith DG, Aronson JK, Oxford Textbook of Clinical Pharmacology and Drug Therapy. Oxford: Oxford University Press; 1992.

16. Gibson JD, Pumford NR, Samokyszyn VM, Hinson JA. Mechanism of acetaminophen-induced hepatotoxicity: Covalent binding versus oxidative stress. Chem Res Toxicol 1996;9:580-5.

17. El-Hady E, Kandil AM, Hassan WA, Ahmed AY. Comparative study of the effect of taurine, caffeine, and/or paracetamol on male fertility and teratogenicity in rats. J Pharm Pharm 2018;5:1-7.

18. Wassef B, Kohansieh M, Makaryus AN. Effects of energy drinks on the cardiovascular system. World J Cardiol 2017;9:796-806.

19. Zulli A, Smith RM, Kubatka P, Novak J, Uehara Y, Loftus H, et al. Caffeine and cardiovascular diseases: Critical review of current research. Eur J Nutr 2016;55:1331-43.

20. Bearden HJ, Fuquay JW. Applied Animal Reproduction. Reston, VA: Reston Publishing Company, Inc.; 1980.

21. Erel O. A new automated colorimetric method for measuring total oxidant status. Clin Biochem 2005;38:1103-11.

22. Barth R, Counce S, Smith P, Snell GD. Strong and weak histocompatibility gene differences in mice and their role in the rejection of homografts of tumors and skin. Ann Surg 1956;144:198-204.

23. McClain RM, Becker BA. Teratogenicity, fetal toxicity, and placental transfer of lead nitrate in rats. Toxicol Appl Pharmacol 1975;31:72-82.

24. Ghosal S, Chakraborty I, Pradhan NK. Jussiaea repens (L) induced morphological alterations in epididymal spermatozoa of rat. Int J Pharm Sci Rev Res 2013;22:288-95.

25. Bowman W, Rand $M$. The reproductive system and drugs affecting the reproductive systems. Textb Pharmacol 1985;20:1-8.

26. Ekaluo U, Ikpeme E, Udokpoh A. Sperm head abnormality and mutagenic effects of aspirin, paracetamol and caffeine containing analgesics in rats. Int J Toxicol 2009;7:1-9.

27. Krishnamoorthy P, Vaithinathan S, Rani VA, Bhuvaneswari A. Effect of Terminalia chebula fruit extract on lipid peroxidation and antioxidative system of testis of albino rats. Afr J Biotechnol 2007;6:1888-91.

28. Shashi A, Imtiaza K. Alleviation of fluoride induced alterations in antioxidant status and fecundity of spermatozoa of rates by Boerhaavia diffusa L. Int J Pharm Pharm Sci 2017;9:93-104.

29. Ratnasooriya WD, Jayakody JR. Long-term administration of large doses of paracetamol impairs the reproductive competence of male rats. Asian J Androl 2000;2:247-55.

30. Rodemann HP, Goldberg AL. Arachidonic acid, prostaglandin E2 and F2 alpha influence rates of protein turnover in skeletal and cardiac muscle. J Biol Chem 1982;257:1632-8.

31. Obochi GO, Amali OO, Ochalefu DO. Effect of melatonin and caffeine interaction on caffeine induced oxidative stress and sleep disorders. Niger J Physiol Sci 2010;25:17-24.

32. Vandenburgh HH, Shansky J, Solerssi R, Chromiak J. Mechanical stimulation of skeletal muscle increases prostaglandin F2 alpha production, cyclooxygenase activity, and cell growth by a pertussis toxin sensitive mechanism. J Cell Physiol 1995;163:285-94. 